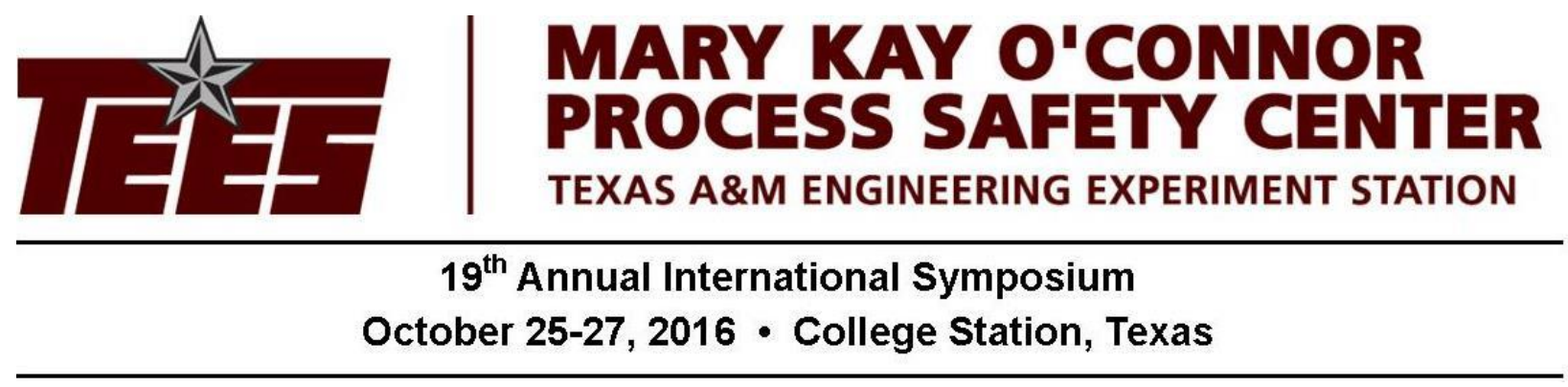

\title{
Mitigation of Industrial Hazards by Water Spray Curtains
}

\author{
Jean-Marie Buchlin \\ von Karman Institute for Fluid Dynamics \\ Chaussée de Waterloo 72 \\ B-1640 Rhode-St-Genèse \\ Belgium \\ buchlin@vki.ac.be
}

\begin{abstract}
A Nowadays, the water spray curtain is recognized as a useful technique to mitigate major industrial hazards. It combines attractive features such as simplicity of use, efficiency and adaptability to different types of risks. In case of accidental toxic gas releases, the spray curtain may be used as a direct-contact reactor exchanging momentum, heat and mass with the gas phase. The cloud is diluted, warmed, and if toxic, some of its toxic content can be absorbed by the droplets to which chemical reactants can be added. In case of fire, water sprays can provide thermal shielding to maintain the integrity of storage tanks. The curtain behaves as a filter and can produce significant attenuation of the incident radiation that impinges on crucial structures such as petro-chemical storage tanks.
\end{abstract}

Both of these applications have been thoroughly investigated at the von Karman Institute The outcomes of these research projects is a comprehensive engineering code simulating on the one hand the forced dispersion, heating and physico-chemical inhibition of cold pollutant clouds and on the other hand the thermal shielding performance of a water curtain. The numerical approach is supported by laboratory (including wind tunnel tests) and field tests dedicated to investigate the effects of numerous operating parameters on the water spray curtain efficiency and to build a data base for model validation.

The paper gives an overview of the main features of the modeling and on practical industrial applications with a special focus on the adequate water curtain operating conditions and the influence of environmental factors. 


\section{General Introduction}

The mitigation of major industrial hazards associated to the formation of toxic and/or flammable gas clouds as well as the formation of pool fire is one of the highest preoccupation in the petro-chemical world.

Nowadays, the mitigation technique involving water spray curtains is spreading more and more in industrial storage sites in the light of their simplicity, flexibility and effectiveness. The principle consists to place on the path of the cloud or fire radiant emission water fence either to dilute the pollutant concentration or to attenuate the heat flux.

In this regard, the paper presents the achievements accomplished at the von Karman Institute in the modeling of water spray curtain as means for forced dilution of heavy gas cloud and thermal shielding, respectively.

\section{Forced dilution of heavy gas clouds}

To evaluate the performance of water curtain as diluting and dispersing system a research program has been conducted by the VKI in collaboration with the Institut des Technologies Chimiques (ITC) and the LAGEP of the University Claude of Lyon and the Institut des $\underline{\mathbf{S}}$ ciences des Risques (ISR) of the École des Mines d'Alès with the support of GDF Suez and Total. Although the methodology adopted was focused on the different effects of mechanical dispersion, cloud warming and pollutant absorption yielded by water curtains, the paper only reports the part dealing with force dispersion of heavy gas clouds; The approach includes three specific phases:

- Field test with spray nozzles of industrial type [1]

- Laboratory experiments in a wind gallery [2-3]

- Multidimensional CFD simulation [4-5]

The final outcome is an engineering code, named CASIMIRE (Code pour l'ÁAide à la

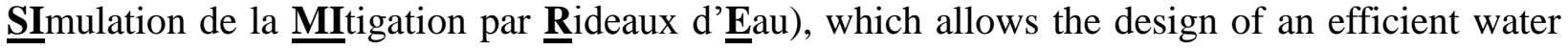
curtain according to accidental release scenario. Moreover, it gives also a comprehensive view of the effects of the main parameters and provides useful guidelines for safety engineers.

\section{$\underline{\text { Curtain definition }}$}

The water curtain can be composed of one or several banks of spray nozzles each one separated by the distance $E_{r}$ as sketched in figure 1. Each bank is equipped by $N_{n}$ water-pressurized nozzles characterized by the flow number, FN, defined as the ratio of the mass flow rate of the nozzle divided by the square root of the supply pressure, $\Delta P$. Therefore the mass flow rate per unit of curtain length is expressed as: 


$$
\dot{m}_{\ell, u}=n_{n} F_{N} \sqrt{\Delta P}
$$

Where $n_{n}$ is the nozzle density $(\# / m)$. In general the nozzle pitch is chosen such that the sprays overlap to form a dense cloud of droplet.

The spray is a polydispersed two-phase flow. Measurements performed with Laser Phase Doppler Interferometer have shown that the droplet size distribution can be modeled by the Rosin-Rammler law or the LogNormal law and that the mean characteristic droplet diameter, SMD, can be expressed in function of the equivalent nozzle diameter, Do, and liquid pressure: [6]:

$$
S M D=\frac{\sum_{i=1}^{N_{d}} d_{i}^{3} \cdot n\left(d_{i}\right)}{\sum_{i=1}^{N_{d}} d_{i}^{2} \cdot n\left(d_{i}\right)}=C_{o} \frac{D_{o}^{\frac{2}{3}}}{\Delta P^{\frac{1}{3}}}
$$

Where $n\left(d_{i}\right)$ represents the number of droplet belonging to class of diameter $d_{i}$ and $N_{d}$ the number of classes used to describe the droplet population. $\mathrm{C}_{\mathrm{o}}$ is a constant of the order of 1 , which depends of the nozzle design.

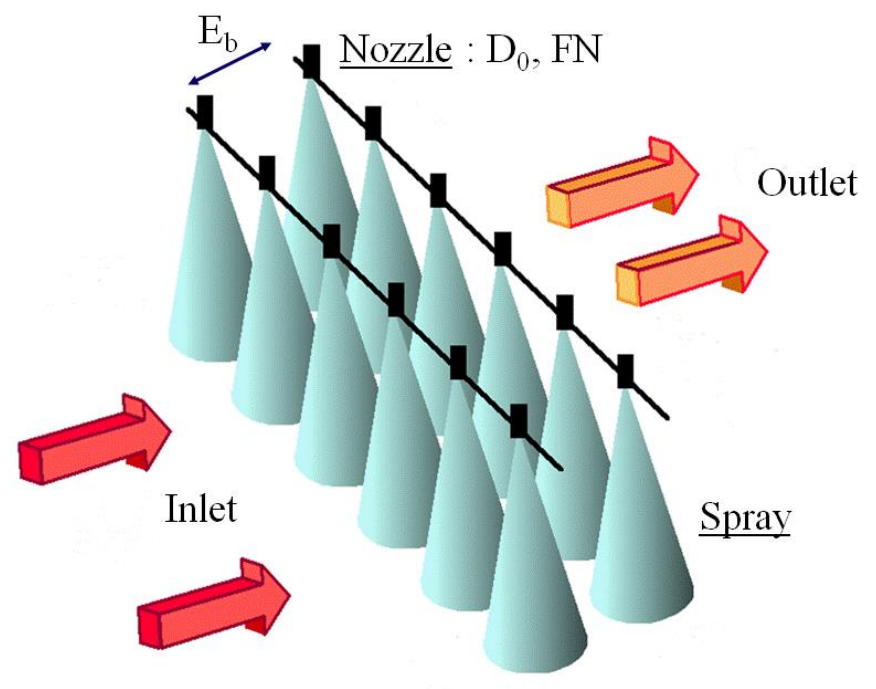

Figure 1: Water Spray Curtain

\section{$\underline{\text { Field Tests }}$}

The field tests have been performed on the supervision of the ISR on two different sites: the first campaign took place at the Camp des Garrigues, military field close to Nîmes and the 
second on the experimental platform at the Total oil refinery of Lavéra, both in France [1].

Two downward water curtains have been tested. The first one is $5 \mathrm{~m}$ long and $2 \mathrm{~m}$ high. The second is $10 \mathrm{~m}$ long and its height could be adjusted between $2 \mathrm{~m}$ and $3 \mathrm{~m}$. They were composed of Lechler nozzles with initial full cone spray angle of $90^{\circ}$. The nozzle diameter could vary from $3.6 \mathrm{~mm}$ to $8 \mathrm{~mm}$. The maximum number of nozzle was 25 and 50, respectively. The operating water pressure was ranging from $300 \mathrm{kPa}$ to $700 \mathrm{kPa}$ and the linear flow-rate from $20 \mathrm{~kg} / \mathrm{min} . \mathrm{m}$ to $225 \mathrm{~kg} / \mathrm{min} . \mathrm{m}$. The curtain was always placed normal the main wind direction. The tests involved releases of Chlorine and Carbon dioxide. They are heavy non flammable and weakly soluble gases. Their properties allow the study of the net effect of forced dilution due to water spray curtains.

The measurement techniques rely on the trapping of chlorine in soda solution, the analysis of which is made a posteriori in laboratory. That leads to average value of the concentration. However, in case of $\mathrm{CO} 2$, instantaneous measurements have been realized by means of IR probes. In all the experiments the data gathering is performed at the ground. A meteorological station allows the measurement of the wind speed $(1 \mathrm{~m} / \mathrm{s}$ to $4 \mathrm{~m} / \mathrm{s})$ by means of an ultrasonic anemometer, the ambient temperature $\left(15^{\circ} \mathrm{C}\right.$ to $\left.25^{\circ} \mathrm{C}\right)$ and the relative humidity $(40 \%-70 \%)$.

The field tests allow the study of parameters effect, such as the release flow rate $(1 \mathrm{~kg} / \mathrm{min}$ to $25 \mathrm{~kg} / \mathrm{min}$ ), meteorological conditions (from week to moderate wind), type of the nozzle, supply water pressure on the water curtain performance. Figure 2 shows a typical view of a Lavera test and points out the dominant obstacle effect of the curtain on the cloud.

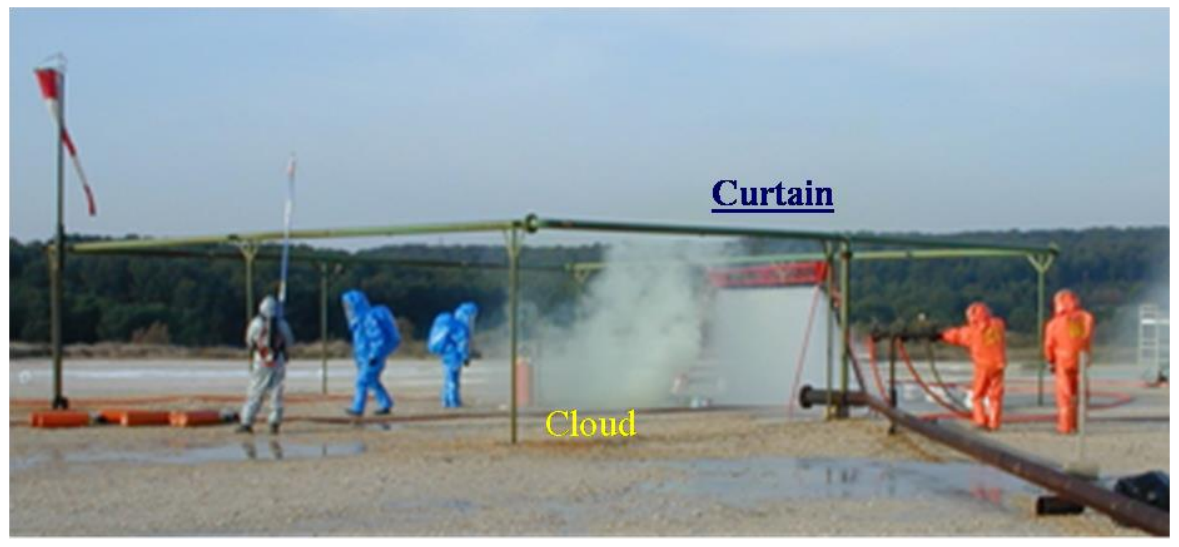

Figure 2: View of Field test with $\mathrm{Cl} 2$ cloud.

\section{$\underline{\text { Wind Gallery tests }}$}

In parallel to field tests, experiments at small scale have been conducted in the VKI $\underline{\text { Wind }}$ 
Gallery (WG). This approach throws off the variability of atmospheric conditions in working a constant wind speed. Figure 3 shows a schematic of the Wind Gallery.

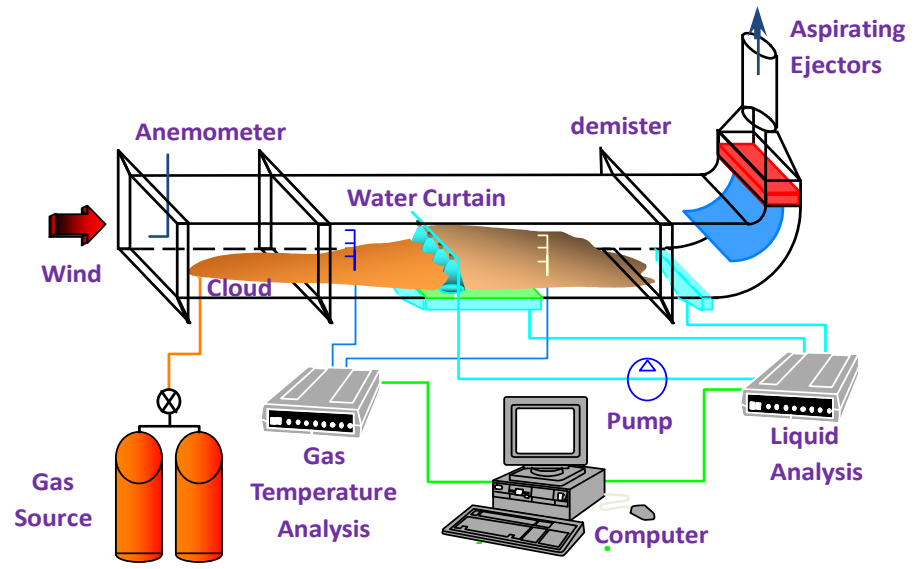

Figure 3 : Schematic of the Wind Gallery testing procedure

The WG is $7 \mathrm{~m}$ long with a rectangular cross section of $1 \mathrm{~m}$ high and $1.3 \mathrm{~m}$ wide. Four pump ejectors mounted at the exit of the facility allows an air stream which can simulate real wind of $1 \mathrm{~m} / \mathrm{s}$ to $10 \mathrm{~m} / \mathrm{s}$. The water curtain is composed of nozzles at scale $1 / 4$ compared to those used in field tests. The curtain spans over all the width of the test section and can work in downward or upward modus operandi. The ground of the test section is porous to allow the water recovery; the hydraulic circuit operate in close loop.

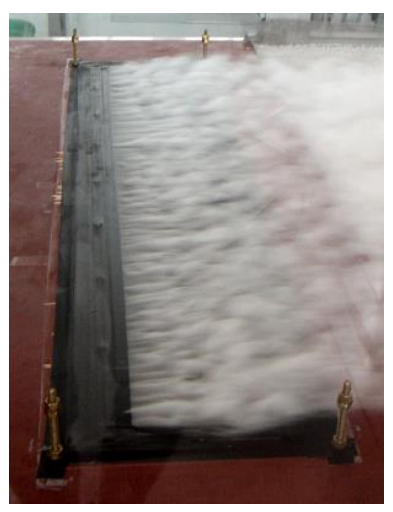

Cloud release

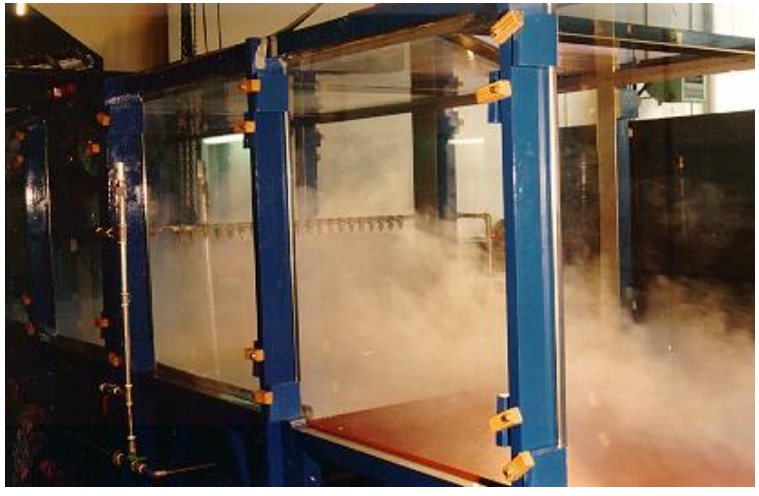

Spray curtain

Figure 4: Visualization of cloud behavior

The cloud is generated by injecting at the inlet of the tunnel and along all the width of the floor, gas such a SF6, or CO2. It is worthwhile mentioning that air-N2 mixture was also used to investigate the thermal heating of cold cloud $\left(-50^{\circ} \mathrm{C}\right)$ induced by water curtain. Vertical concentration profiles are measured by means of isokinetic sampling probes connected to a hot wire device developed at the VKI. Figure 4 shows some visualizations of the cloud behavior. A large recirculation bubble forms upstream the operating curtain as observed during field tests. In 
the WG, tests have been dedicated to evaluate the effect of the ratio curtain height to cloud thickness, wind speed and modus operandi.

Numerical simulation

The CFD simulation of the forced dilution of pollutant cloud by water curtain have been performed with different codes, VKI in-house codes [5, 7]] and ANSYS code Fluent [1,8]. The flow of gaseous phases are modeled by the Navier-Stokes equations with a turbulent RNG k- $\varepsilon$ model. The droplet motion is described by a Lagrangian tracking. The spray is modeled by a limited number of trajectories, each one characterized by a liquid flow rate and a droplet size distribution to take into account the poly-dispersed nature of the droplet flow. A typical 2D representation of the gas flow and concentration field is displayed in figure 5. In the case of downward curtain modus operandi an upstream recirculation zone is formed while the upward modus operandi leads to a downstream recirculation zone.

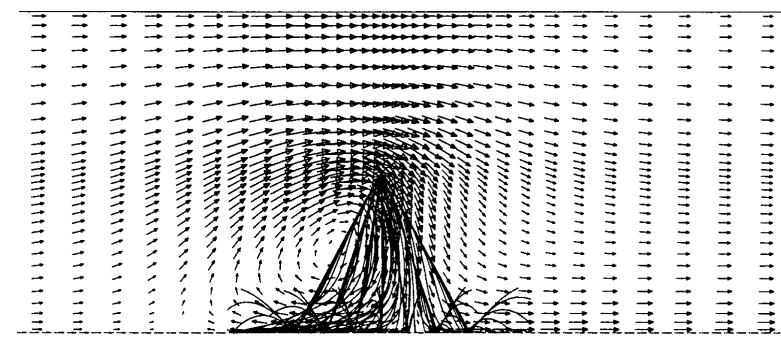

(a) Downward curtain

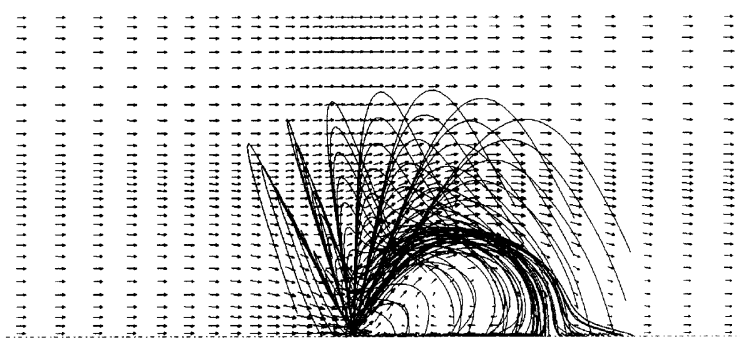

(b) Upward curtain

Figure 5 : CFD simulation of gas flow in presence of water curtain.

\section{$\underline{\text { Main Results }}$}

The performance of a water spray curtain can be expressed by the dilution factor, FD, or the dilution efficiency, $\eta_{D}$, defined as following:

$$
\mathrm{F}_{\mathrm{D}}=\frac{\rho_{\mathrm{p}, \text { free }}}{\rho_{\mathrm{p}, \text { forced }}} \quad \text { and } \quad \eta_{\mathrm{D}}=\frac{\rho_{\mathrm{p}, \text { free }}-\rho_{\mathrm{p}, \text { forced }}}{\rho_{\mathrm{p}, \text { free }}}=1-\frac{1}{\mathrm{~F}_{\mathrm{D}}}
$$

Where $\rho_{p}$ is the mass concentration of the pollutant. To quantify the resistance of the curtain to the wind, the momentum ratio is introduced:

$$
\mathrm{R}_{\mathrm{M}}=\frac{\dot{\mathrm{m}}_{\ell, \mathrm{u}} \cdot \mathrm{U}_{\mathrm{d} 0}}{\rho_{\mathrm{g}} \mathrm{U}_{\mathrm{w}}{ }^{2} \mathrm{H}_{\mathrm{r}}}
$$

Where $\dot{\mathrm{m}}_{\ell, \mathrm{u}}$ is the water mass flow rate per unit length of curtain and $\mathrm{U}_{\mathrm{do}}$ the liquid velocity at the nozzle exit, $\rho_{\mathrm{g}}$ the gas density, $\mathrm{U}_{\mathrm{W}}$ the wind speed and $\mathrm{H}_{\mathrm{r}}$ the height of the curtain. In Figure 6 one can appreciate the dilution effect due to water curtain. The typical spanwise distribution of the pollutant concentration measured at the ground and downstream the curtain during field tests 
is plotted. $R_{M}=0$ corresponds to the free dispersion. At small values of $R_{M}$, typically 2 , the distribution exhibits a Gaussian type behavior as without curtain. As $R_{M}$ increases and exceeds a typical threshold value of 5 the spray curtain flattens and the concentration distribution becomes more uniform. The dilution efficiency grows as $R_{M}$ augments and may reach value of $90 \%$ as $R_{M}$ approaches 10 .

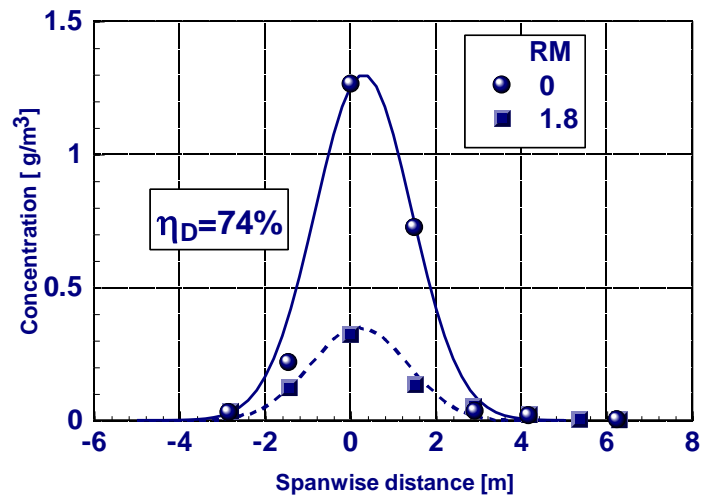

(a)

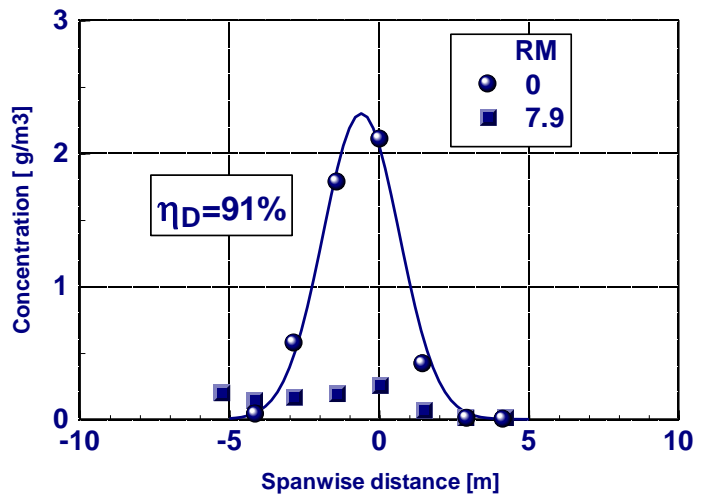

(b)

Figure 6 : Spanwise distribution of concentration at the ground.

Figure 7 displays the vertical profile of the pollutant concentration measured in WG. The action of the curtain is more pronounced at the ground where the initial cloud concentration is very high: it is also characterized by a very good uniformity of the vertical concentration profile. This is the reason why the global performance of the water curtain can be only based on the ground measurements.

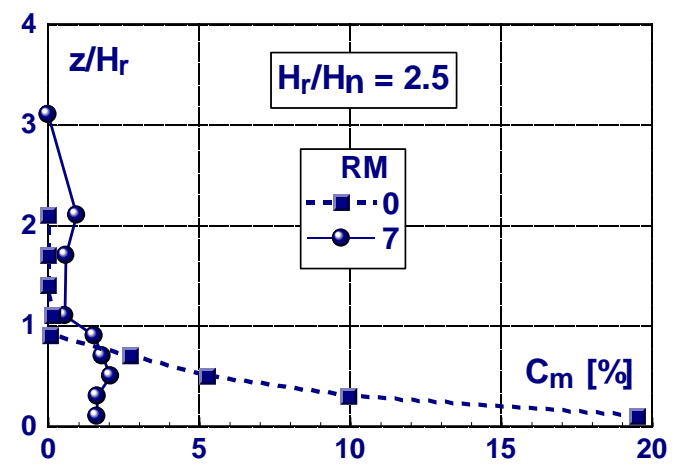

Figure 7 : Vertical concentration profile

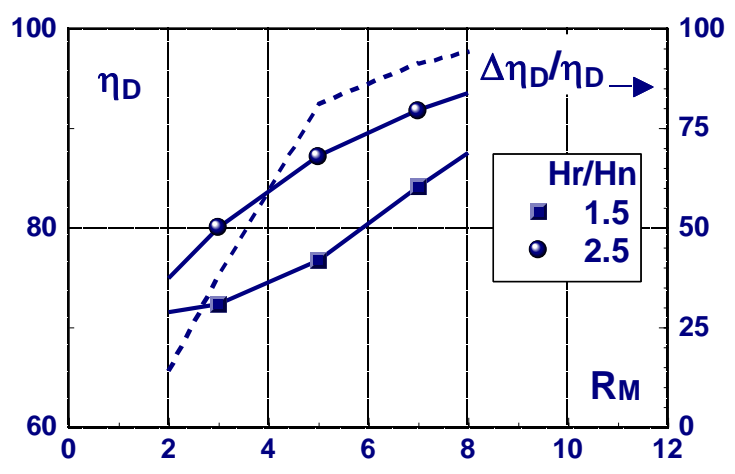

Figure 8: Effect of the $\mathrm{H}_{\mathrm{r}} / \mathrm{H}_{\mathrm{n}}$ on $\eta_{D}$.

Figure 8 emphasizes the effect of $R_{M}$ and the curtain height to cloud thickness ratio, $\mathrm{H}_{\mathrm{r}} / \mathrm{H}_{\mathrm{n}}$, on the curtain effectiveness. As already obtained during field tests, significant dilution efficiency can be obtained at $\mathrm{R}_{\mathrm{M}}$-value larger than 8. Moreover, the increase of the curtain height yields better performance. 
Finally a comparison of the three approaches followed is presented in Figure 9. Taking into account the inevitable differences between test conditions, nozzles and limitation of CFD, one can conclude that the agreement is good and that an engineering correlation can be established.

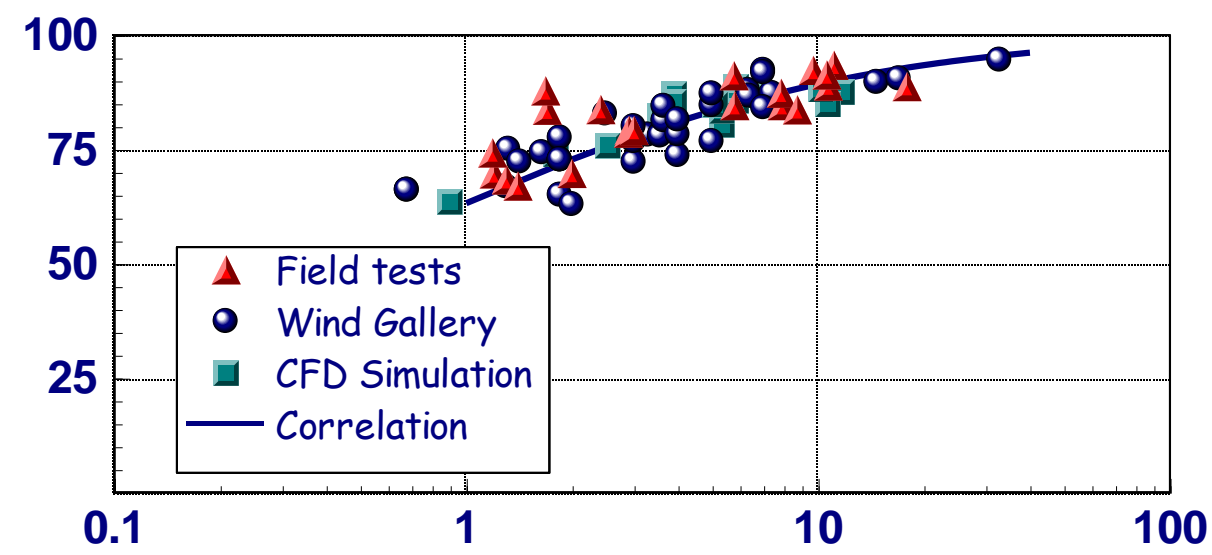

Figure 9 : Dilution efficiency of water spray curtain

\section{CASIMIRE, an Engineering Design Code of Water Curtain}

Short code description

The physical modeling upon which relies the engineering code, named CASIMIRE, involves mass, momentum and energy balance of the two-phase flow. It is shortly described hereafter. The mass balance expresses that the gas flow rate inside the spray varies according to the external gas entrainment provoked by the momentum exchange between the two phases and the liquid droplet evaporation. The momentum change of the two-phase flow is due to the presence of the body force modeled by the apparent weight of the particulate phase. The enthalpy change of the two-phase flow is the result of the input from the external gas entrainment and possible phase change of the liquid droplet (evaporation and freezing).

Lagrangian approach is adopted to model the droplet phase behavior. The momentum, heat and mass transfer can be expressed by the same generic equation applied to each droplet class $i$ :

$$
\frac{\mathbf{d} \Theta_{i}}{\mathbf{d} t}=\frac{\Delta \Theta_{i}}{\tau_{i}}+S_{i}
$$

Where $\Theta_{i}$ can be either the velocity, the temperature or the mass of the droplet $i$, respectively and $\tau_{I}$ is the relaxation time of the transport to be considered; this characteristic time is a strong function of the droplet Reynolds number through the drag coefficient (momentum), the Nusselt number (heat transfer) and the Sherwood number (mass transfer). $S_{i}$ represents the source term; it is the buoyancy force in the momentum equation and is the latent heat of vaporization and the radiation contribution in the thermal equation. 
CASIMIRE code includes different data bases. One is dedicated to spray nozzles that are characterized in terms of flow number and droplet size distribution modeled by a Lognormal formulation. Another provides the physic-chemical properties of about 20 gases. In forced dilution mode, the main inputs of the code are the type of nozzle and the spacing, the modus operandi of the curtain with its height and the temperature and the pressure of the water. The cloud is characterized by its thickness and the mean pollutant concentration. The atmosphere by the wind speed, air temperature and relative humidity. The main outputs are the pollutant concentration and the temperature of the cloud behind the curtain as well as the global performance (dilution efficiency and heating factor).

\section{Typical Results for Forced Dispersion}

The wind effect investigated through experimental and CFD approaches have been modeled and implemented in the CASIMIRE code by using correlation plotted in figure 9. As an example of the code applicability the following scenario is considered. A chlorine release of 3.5 $\mathrm{kg} / \mathrm{s}$ leads to cloud which spreads on the ground with a rectangular cross-section of aspect ratio equal to 10. Computer code developed at the VKI to predict free dispersion of heavy gas according to Pasquil-Turner classes, allows the determination of mean pollutant concentration and height of the cloud at the curtain location. The atmosphere is at $20^{\circ} \mathrm{C}$ with $60 \%$ of relative humidity. The water spray curtain is $3 \mathrm{~m}$ high. It is composed of $65^{\circ}$-full cone spray nozzles with orifice diameter of $5 \mathrm{~mm}, 7 \mathrm{~mm}$ and $10 \mathrm{~mm}$, respectively. The nozzles are spaced of $0.5 \mathrm{~m}$. The water temperature is $15^{\circ} \mathrm{C}$ and the relative supply pressure is $800 \mathrm{kPa}$. Figure $10 \mathrm{a}$ shows the evolution of the dilution efficiency as the wind speed increases from $1 \mathrm{~m} / \mathrm{s}$ to $5 \mathrm{~m} / \mathrm{s}$. Performance of spray curtain made of the smallest nozzles degrades very quickly as the wind speed increases: there, the sprays are mainly composed by small water droplets, which are thrown away by the wind before impacting the cloud. Water curtains composed of larger spray nozzles sustain better the detrimental effect of the wind. Figure $10 \mathrm{~b}$ points out that there exists a trade off about the choice of the nozzle size. It is more pronounced at high wind speed. Indeed, curtain made of small nozzles will be strongly affected by the wind due to the small size of the droplets while curtain with large nozzles will resist better to wind momentum but on the other hand will entrain more pollutant. Therefore, it exists an optimum nozzle diameter, which however may vary according to the atmospheric conditions (wind). 


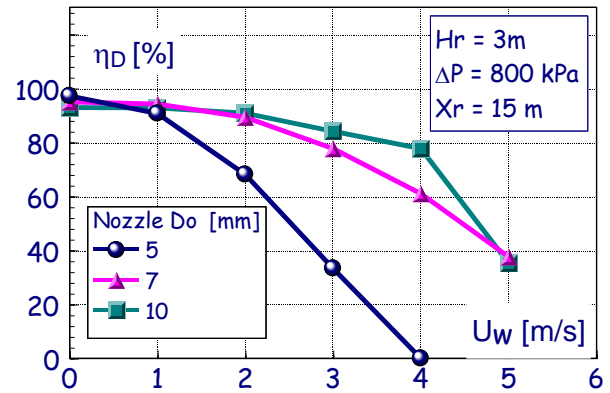

(a) Wind speed

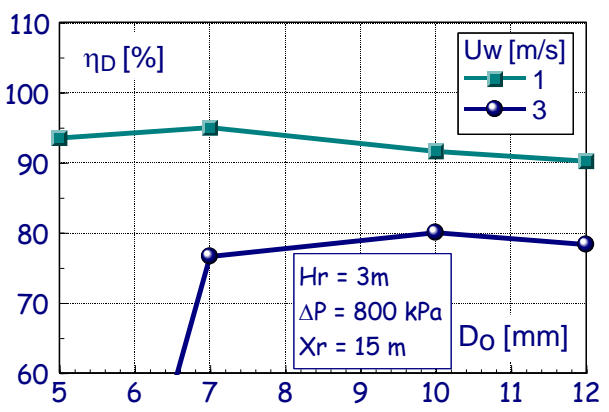

(a) Nozzle orifice diameter

Figure 10 : Parameter effect on the forced dilution efficiency.

Conclusions on the forced dilution by water spray curtains

A methodology based the three fundamental approaches of Applied Research, the CFD, the laboratory modeling and the field test, shows that water spray curtain appropriately designed for a scenario of heavy gas release can provide a valuable mitigation result.

The mechanical action of water spray curtain provokes an important decrease of the downstream concentration, which at the same time exhibits a uniform profile. The design of the curtain must ensure a momentum ratio as high as 10 and a height at least two times superior to that of the cloud. In such conditions a dilution efficiency of $90 \%$ can be expected.

Illustrative exercise performed with the engineering design code CASIMIRE exemplifies some rules of good practice.

- The water spray curtain is efficient at low and moderate wind. Above wind speed of $5 \mathrm{~m} / \mathrm{s}$ its use may call into question.

- For a given scenario there exists a curtain height and a nozzle size which lead to an optimum tradeoff concerning the gas entrainment and the resistance to the wind.

- In general it is advised to place the curtain no so far from the release whilst avoiding that it affects the pollutant source (water on pollutant liquid pool).

\section{Thermal Shielding by Water Spray Curtains}

A water pulverization sited in the way of a incident radiative heat flux can afford interesting thermal shielding. Therefore, water spray curtain appears to be an relevant candidate to protect structure against fire radiation. Such a mitigation technique has been studied at the VKI in the framework of the European ASTRRE project in collaboration with the Institut des Technologies Chimiques (ITC), the LAGEP of the University Claude Bernard and the Centre de Thermique de l'INSA (CETHIL), all from Lyon (France) $[9,10,11]$. 
The water spray curtain can operate vertically as in the forced dispersion situation but it may also be oriented horizontally hitting the wall to be protected as illustrated in Figure 11. In this case, the mist is accompanied by a liquid film falling down along the wall (figure 11b). Such protection technique has exclusively developed at the VKI $[12,13]$.

These two types of shielding have been again investigated through laboratory experiments and field tests, the results of which are intended to validate physical models implemented in CASIMIRE code.
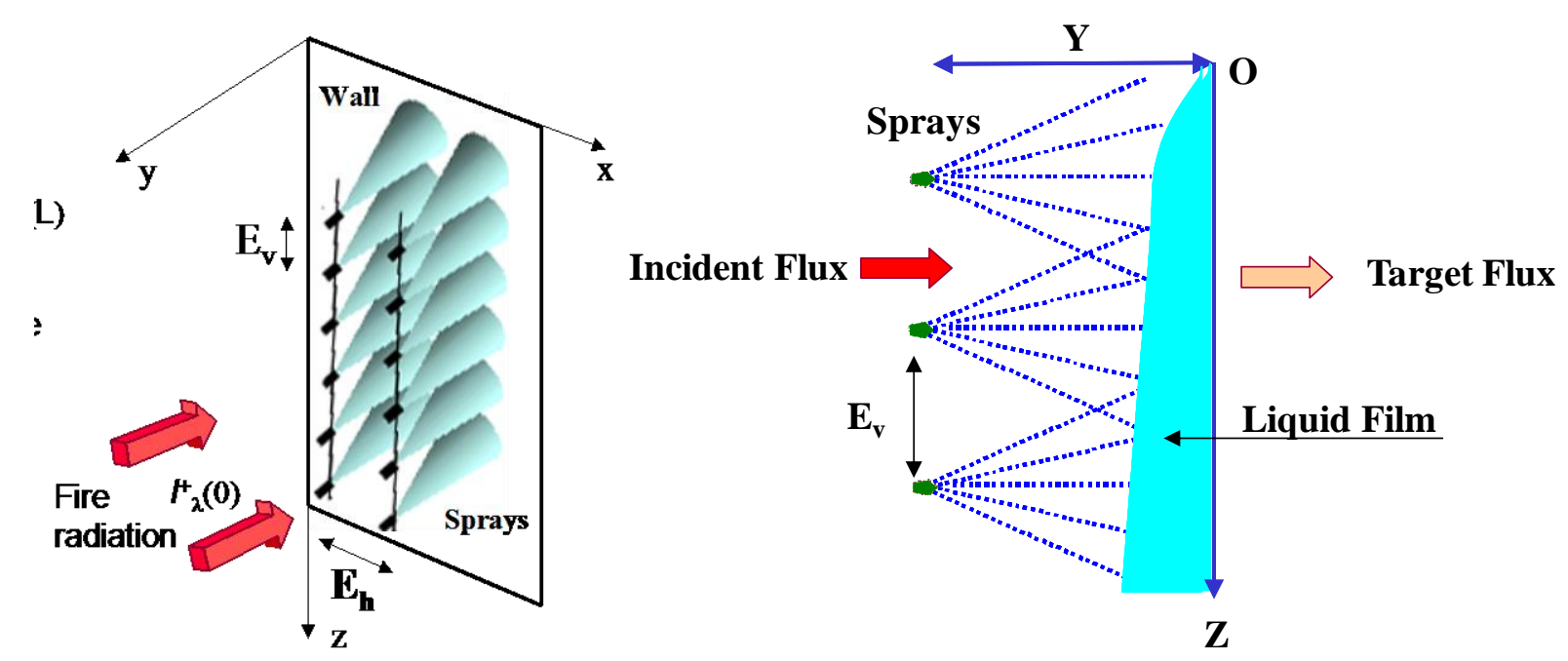

Figure 11 : Thermal shielding by impinging water sprays

\section{Physical modelling}

To model the radiant heat transfer, the spray is regarded as a semi transparent medium inside which series of physical spectral mechanisms such as absorption, emission and scattering takes place in the gas (vapor content) and droplet phases. These different mechanisms contribute to the attenuation of the incident flux through the curtain, the enthalpy of which varies accordingly. The radiant heat transfer is modeled by the discrete ordinate method [11]. Considering only the horizontal direction of propagation the model is reduced to the so-called Two-Flux model described in detail in [10]. It consists of a system of two equations describing the variation of the spectral hemispherical intensity forward, $I \lambda^{-}$, and backward, $I \lambda^{+}$. The important quantity, which interests the safety engineer, is the total attenuation factor afforded by the curtain:

$$
A=1-\left[\int_{0}^{\infty} I_{\lambda}^{+}(E) d \lambda\right] /\left[\int_{0}^{\infty} I_{\lambda}^{+}(0) d \lambda\right]
$$


Where $\mathrm{E}$ is the thickness of the curtain. Numerical simulation shows that the total attenuation factor can be satisfactorily approximated in a macroscopic way by the Beer-Lambert's law (B-L):

$$
A=1-e^{-\kappa_{s}}
$$

Where the optical thickness, $\mathrm{K}_{\mathrm{s}}$, can be modeled as following:

$$
\kappa_{s}=\frac{3}{2} \frac{\dot{m}_{\ell, u}}{\rho_{\ell} U_{d} S M D}
$$

$U_{d}$ is the mean velocity of the liquid phase in the spray.

In the same way, the B-L formulation is also applied to determine the attenuation due to the falling liquid film produced by the impinging curtain, where the optical thickness can be expressed as following:

$$
\kappa_{f}=\alpha . \delta(z)
$$

Where $\delta(\mathrm{z})$ is the liquid film thickness and $\alpha$ the extinction coefficient determined during experiments carried out on a vertical flat plate heated by gas burner and instrumented with flux meters and triangulation laser probe for the liquid film thickness measurement [14]. Finally the global attenuation factor is given by:

$$
A=1-\mathrm{e}^{-\kappa_{s}} \mathrm{e}^{-\kappa_{f}}
$$

\section{Field Tests}

Several test campaigns at large scale have been organized in the frame of the afore mentioned collaborative European project ASTRRE [9]. A first series of experiments have been carried out in 1996 on the GDF site of Saint-Étienne de Montluc close to Nantes (France). Fires of some dozen $\mathrm{kW} / \mathrm{m}^{2}$ have been realized on a GNL pool of $3 \mathrm{~m}$ wide by $25 \mathrm{~m}$ long. The flames could reach $6 \mathrm{~m}$ high. Two water spray curtains were set in series. The first curtain was $5 \mathrm{~m}$ long. It was composed of full cone spray nozzles of LECHLER FC3 402962 type located at 5m from the ground. The total water flow rate was $250 \mathrm{~kg} / \mathrm{mn}$. The second curtain was $2.25 \mathrm{~m}$ long and composed of full cone spray nozzles of Spraying System 44 TG03 type, positionned at $4.2 \mathrm{~m}$ from the ground with a total flow rate of $11 \mathrm{~kg} / \mathrm{mn}$. Four flux meters were placed $5 \mathrm{~m}$ downstream the curtain unit in the median axis. One flux meter was a Medtherm radiometer the other three have been developped by the CETHIL [15]. Figure 12 shows a schematic of the arrangement (a), a view of a test (b) and of the curtain system (c). 

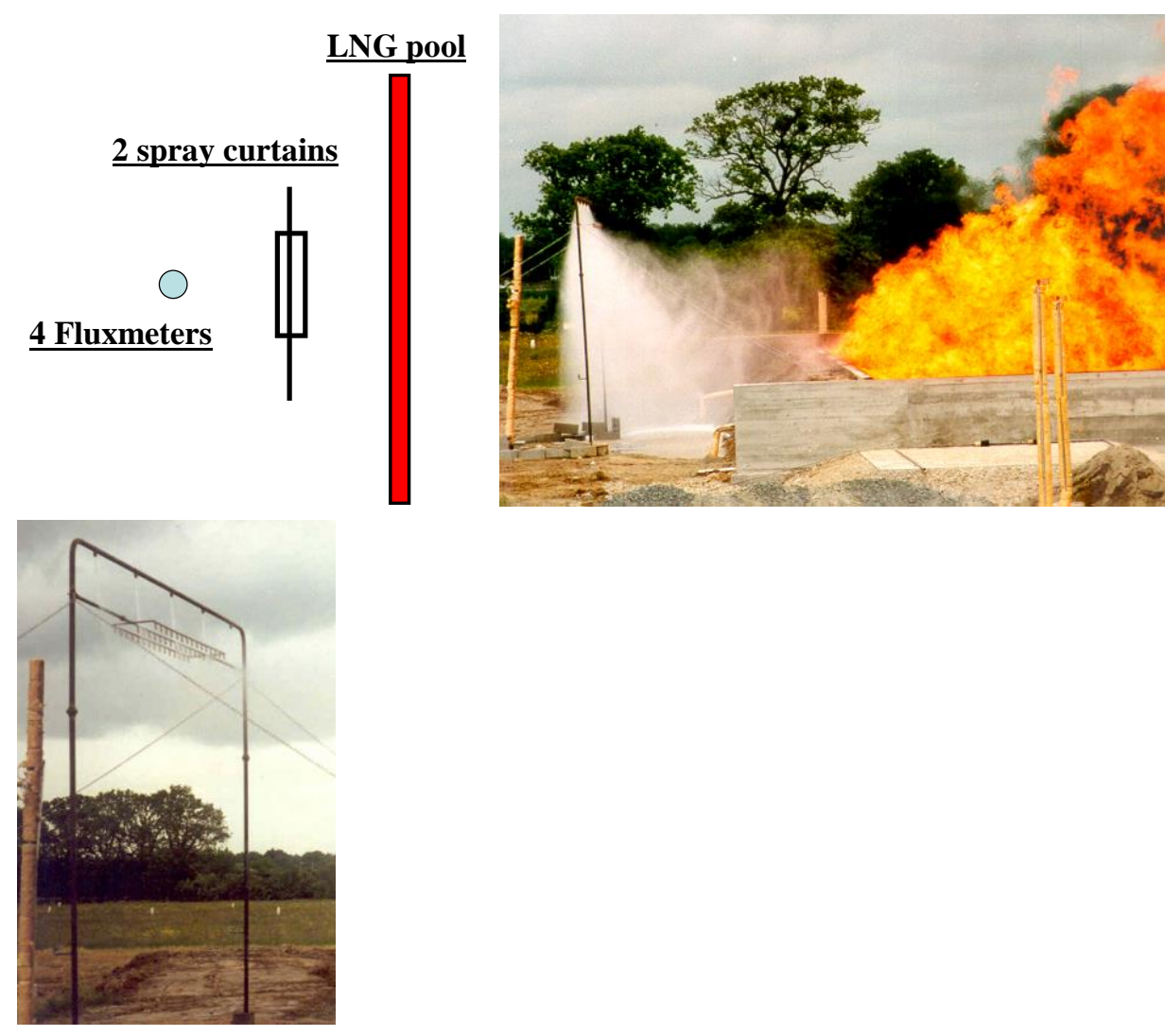

(a) GNL experiment arrangement

(b) GNL test

(c)

Curtain design

Figure 12 : GNL field tests

The second experimental campaign have been carried out on the GESIPE platform close to Vernon (France). The objective was to evaluate the thermal shielding performance of a water curtain in presence of a unleaded gasoline pool fire. About 1000 liters of fuel were ignited in a pond of $2.8 \mathrm{~m}$ in diameter. A downward water barrier was composed by 4 FC3 nozzles spaced $0.75 \mathrm{~m}$ out at $4 \mathrm{~m}$ in altitude. It was working at $700 \mathrm{kPa}$ with a linear flow rate of $80 \mathrm{~kg} / \mathrm{mn}$.m. It was combined with an ascending mobile curtain formed by one $180^{\circ}$ Delta Hydroshield Fire nozzle set down on the ground. This shield provides a water fence of $8 \mathrm{~m}$ long as working at $400 \mathrm{~kg} / \mathrm{mn}$. The curtain system was oriented against the wind, the speed of which $(4 \mathrm{~m} / \mathrm{s}$ and $5 \mathrm{~m} / \mathrm{s})$ was continuously measured by the meteorological station of the SEP close to GESIP. The flux meters involved during the GNL campaigns were also used here.

\section{Laboratory facility}

The laboratory experiments have been conducted in the VKI Water-Spray facility modified to study thermal shield by water spray curtain. The facility allows curtain flow rate up to $1 \mathrm{~kg} / \mathrm{s}$ at $800 \mathrm{kPa}$. Views of the different experimental configurations are proposed in figure 13. The 
radiant source of $10 \mathrm{~kW}$ at $1000 \mathrm{~K}$ is produced by a set of gas burners. The thermal radiation is concentrated by means of an aluminum reflector leading to flux up to $11 \mathrm{~kW} / \mathrm{m}^{2}$ on the target.

The spray curtain is composed of banks of nozzles, the density of which can be varied between 10 and $33 \# / \mathrm{m}$. The nozzles are of full cone type with orifice of $0.51 \mathrm{~mm}$ in diameter and flow number of $F_{n}=6.5710^{-6} \mathrm{~kg} / \mathrm{s}$. $\sqrt{\mathrm{Pa}}$. The test pressure varied from $200 \mathrm{kPa}$ to $800 \mathrm{kPa}$. The typical mean droplet diameter (SMD) obtained is ranged from $50 \mu \mathrm{m}$ to $200 \mu \mathrm{m}$. The droplet velocity varied from $3 \mathrm{~m} / \mathrm{s}$ to $15 \mathrm{~m} / \mathrm{s}$. The local total attenuation factor is deduced from measurement obtained with Medtherm radiometers made of thermopile equipped with RRS-5 protection transparent in the band 1-40 $\mu \mathrm{m}$. These devices are located behind $\mathrm{ZnSe}$ windows of $0.05 \mathrm{~m}$ in diameter implemented on the target wall.

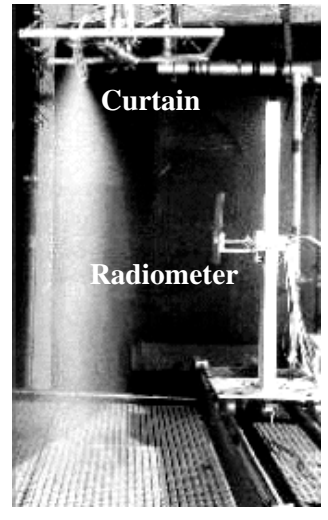

(a) downward configuration

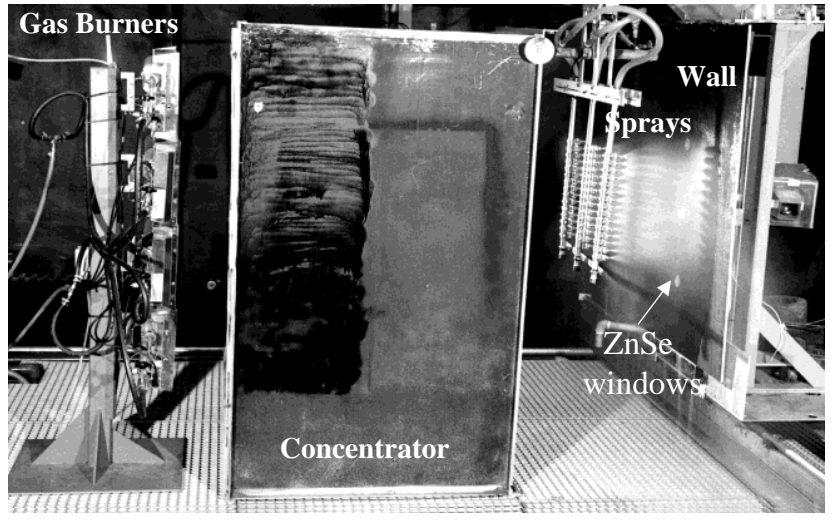

(b) Impinging curtain configuration

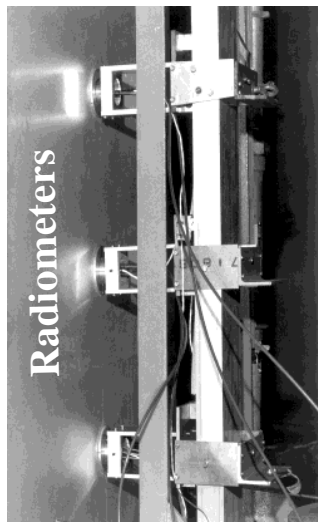

(c) Instrumented target

Figure 13 : Thermal Shielding facility

\section{$\underline{\text { Typical results }}$}

Figure 14 shows the time evolution of the thermal radiation during LNG fire experiment when the water curtain is sequentially on and off. The thermal shielding effect of the water spray curtain is clearly demonstrated since an attenuation of about $70 \%$ can be estimated. 


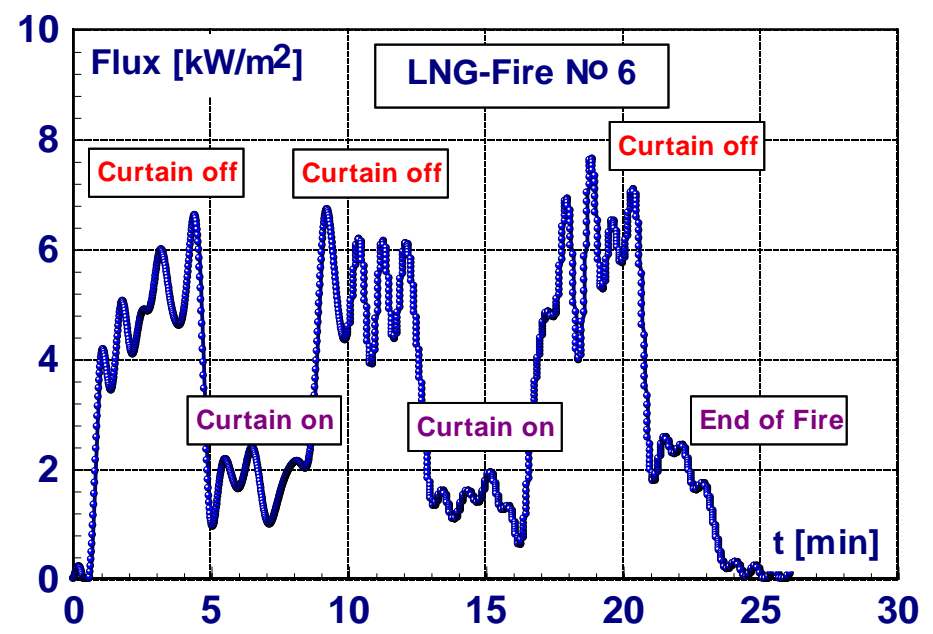

Figure 14 : Thermal radiation during LNG fire experiment

Figure 15 gathers all the field test results. For a given water curtain design, the total attenuation factor increases as the linear flow rate increases; 75\% reduction of the heat flux is obtained in the range of $60 \mathrm{~kg} / \mathrm{mn} . \mathrm{m}-120 \mathrm{~kg} / \mathrm{min} . \mathrm{m}$. Table 1 compares the CASIMIRE prediction to the field test data. The satisfactory agreement observed shows that the numerical code is able to reproduce industrial situation.

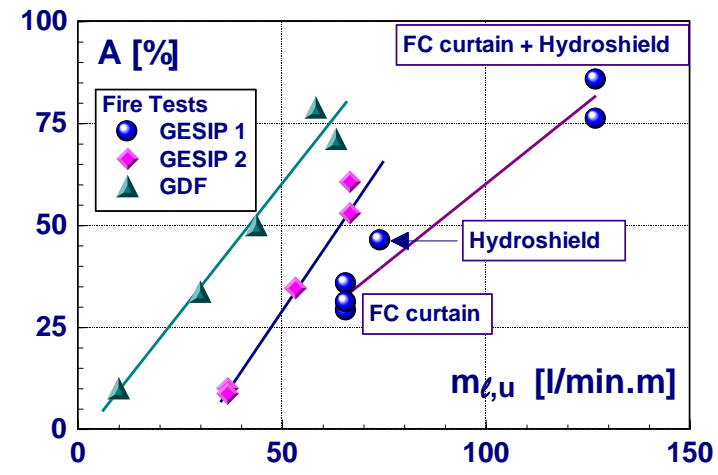

Figure 15: Field test results

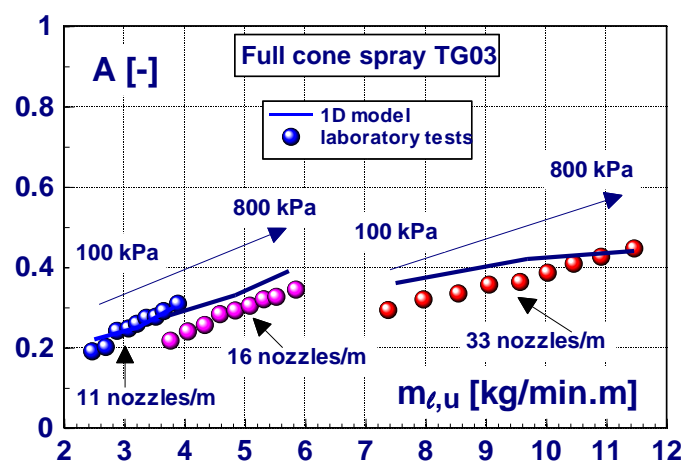

Figure 16 : Laboratory results

Tableau 1: Attenuation factor: Field test - Casimire prediction comparison

\begin{tabular}{|l|c|c|}
\hline Pression $[\mathrm{MPa}]$ & 0.44 & 0.7 \\
\hline Field test & $35[\%]$ & $57[\%]$ \\
\hline CASIMIRE & $45[\%]$ & $60[\%]$ \\
\hline
\end{tabular}

The comparative exercise between experiment and numerical simulation proceeds in Figure 16 with the analysis of the laboratory tests. The agreement is also very satisfying. The pressure 
increase improves the thermal shield performance. Such an effect results from the decrease of the droplet size as the liquid pressure rises: smaller are the droplets higher is their concentration and larger is the liquid surface opposed to the thermal radiation. The augmentation of the nozzle density is another technique to increase the droplet concentration. However figure 16 points out that it is preferable to operate at high pressure with a moderate number of nozzles.

The case of the impinging curtain is exemplified in Figure 17 where the vertical distribution of the attenuation factor measured with Medtherm radiometers is compared to CASIMIRE prediction. The tests have been performed using three vertical banks of nozzles separated by $0.25 \mathrm{~m}$. They were composed $15 \mathrm{TG} 03$ nozzles spaced of $0.03 \mathrm{~m}$. The mass flux was varying from 0.111 to $0.18 \mathrm{~kg} / \mathrm{s} . \mathrm{m}^{2}$. This kind of thermal shielding is characterized by a very high level of attenuation (90\%). The numerical model underestimate the experimental data in the top region because it does not account for the splashing phenomenon, which results in the formation of a liquid film developing upward. Nevertheless, the agreement is very satisfactory given the simplicity of the theoretical model.

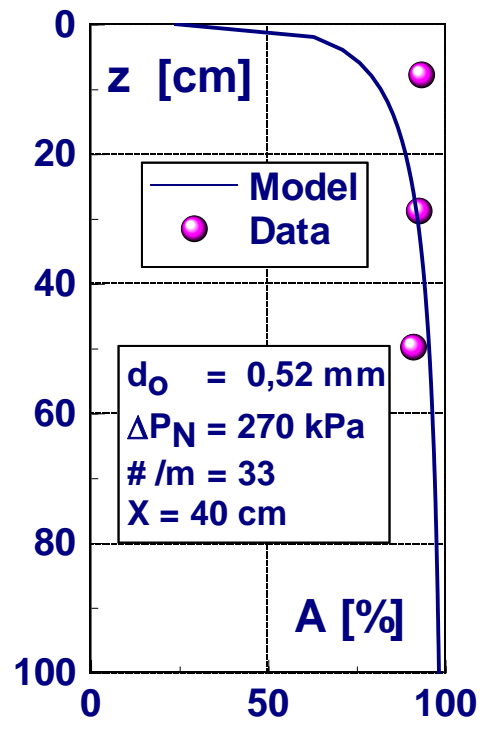

Figure 17: Vertical distribution of the attenuation factor in impinging curtain configuration

\section{Illustrative Industrial application}

To illustrate the applicability of water spray curtain as means for thermal shielding the CASIMIRE code is used.

One considers a circular storage tank of $20 \mathrm{~m}$ high and $20 \mathrm{~m}$ in diameter. It is exposed to thermal radiation of $60 \mathrm{~kW} / \mathrm{m}^{2}$ emitted by a fire the equivalent black body temperature is 
estimated to 1300K. Two scenarios of protection are foreseen. The first one consists in surrounding the tank with a vertical spray curtain. In this case the selected nozzles are of full cone type with an orifice of $6.25 \mathrm{~mm}$ in diameter and a flow number equal to $F_{\mathrm{N}}=9.7 .10^{-4}$ $\mathrm{kg} / \mathrm{s} . \mathrm{Pa}^{0.5}$. The spacing between nozzles is $0.9 \mathrm{~m}$. The hydraulic network can provide pressure up to $1 \mathrm{MPa}$. The relative humidity is $30 \%$ and the ambient temperature $40^{\circ} \mathrm{C}$.

The spectral attenuation predicted after $5 \mathrm{~m}$ downstream after the nozzles is plotted in Figure 18a. A total attenuation of $61 \%$ is obtained. However the vertical distribution of A plotted in Figure 18b points out that the performance degrades significantly in the regions before $4 \mathrm{~m}$ and after $8 \mathrm{~m}$. To address such an issue it is then proposed to install three circular blanks of sprays.; one located at $2 \mathrm{~m}$ above the tank, the second and the third below with an interval of $7 \mathrm{~m}$. Such an arrangement leads to beneficial effect of spray overlapping. Then the nozzle number required is 210 and the total water flow rate is $204 \mathrm{~kg} / \mathrm{s}$. Moreover, the numerical simulation indicates that such shield can sustain windup to $4 \mathrm{~m} / \mathrm{s}$.

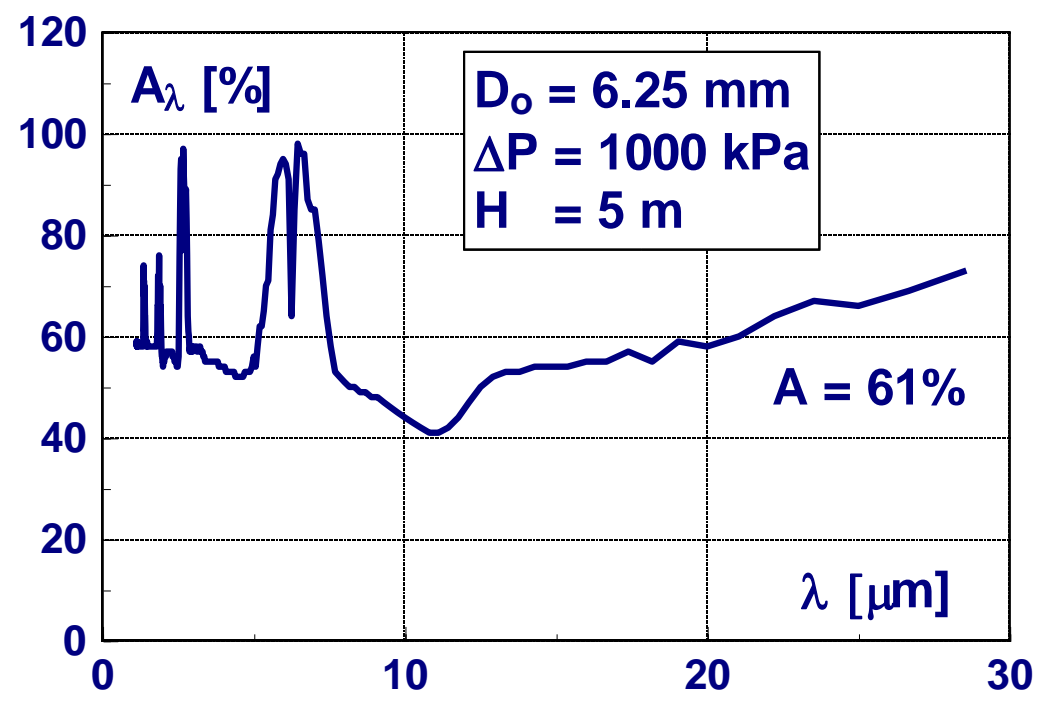

(a) Spectral attenuation

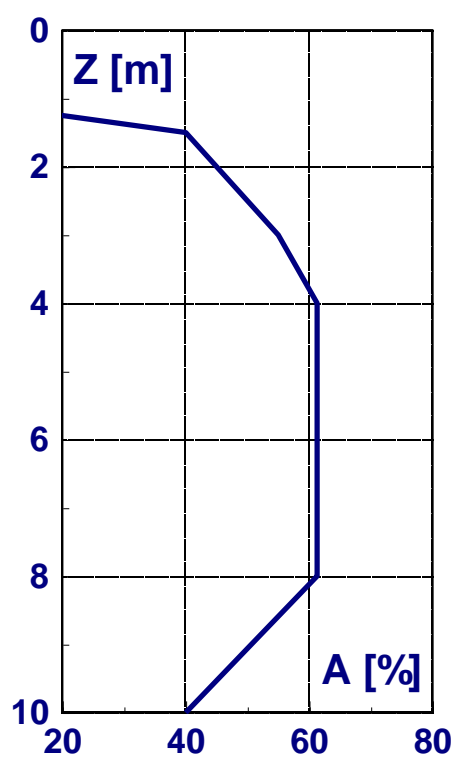

(b) Vertical distribution of attenuation

Figure 18: Attenuation factor with vertical spray curtain

The second scenario involves the impacting spray curtain based on the same previous nozzles which are now oriented horizontally. The thermal shield is now composed of 14 horizontal rows. On each row the nozzle spacing is $1 \mathrm{~m}$, that leads to a total of 867 nozzles. The operating pressure can be decreased down to $200 \mathrm{kPa}$ since the droplet size is not a major parameter in such a design. The total flow rate is $376 \mathrm{~kg} / \mathrm{s}$ equivalent to mass flux of $0.3 \mathrm{~kg} / \mathrm{s} . \mathrm{m}^{2}$. The numerical prediction is shown in Figure 19a. The thermal shielding performance is by far superior to that of the vertical curtain but the water consumption is now $84 \%$ higher. It 
worthwhile emphasizing that in the case of impacting spray curtain, most of the attenuation is afforded by the falling water film, which absorbs the infrared radiation. As a consequence the liquid temperature increases, the same holds for the evaporation or even boiling in poor wetted area. To predict such an occurrence a thermo-hydraulic model of the liquid film has been implemented in the CASIMIRE code. This model includes IR radiation absorption, evaporation, convective heat transfer and enthalpy change due to fresh water flux (spray). The prediction shown in Figure 19b points out that in the present case the water liquid temperature does not exceed $70^{\circ} \mathrm{C}$ and that no performance degradation has to be anticipated. Notice also that the curtain is elevated by $1 \mathrm{~m}$ above of the tank to yield good attenuation factor already at $20 \mathrm{~m}$.

Conclusions on the thermal shielding by water spray curtains

Water spray curtain to shield storage tanks or buildings from thermal radiation emitted by industrial fires proves to be an efficient mitigation technique.

A methodology including physical modeling, laboratory experiments and field tests has been setting up. The outcome is the tuning of CASIMIRE code to simulate the thermal shielding performance of two configurations: the vertical spray curtain and the horizontal impinging spray curtain.

The vertical curtain design may afford total attenuation factor ranging from $50 \%$ to $75 \%$. In such an approach it is recommended to operate with thick curtain at high pressure. Typical water flow rate anticipated is $2 \mathrm{~kg} / \mathrm{s}$ per meter of curtain.

The impacting curtain yields very high attenuation factor, up to $90 \%$, by taking advantage of the formation of falling water film on the wall affording strong IR absorption. Spray overlapping is mandatory and water mass flux comprised between 0.15 à $0.25 \mathrm{~kg} / \mathrm{s} . \mathrm{m}^{2}$ may be foreseen. However, as price of fame such a shielding design should incorporate the prediction of the liquid film temperature to check the possible occurrence of high evaporation and boiling. 


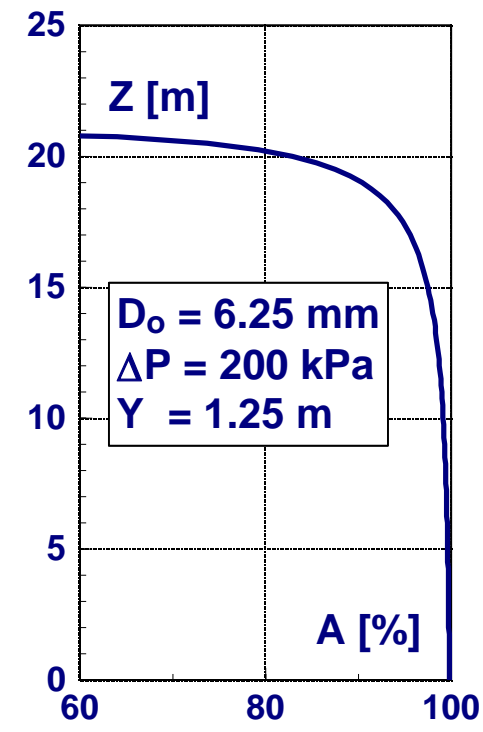

(a) Attenuation factor

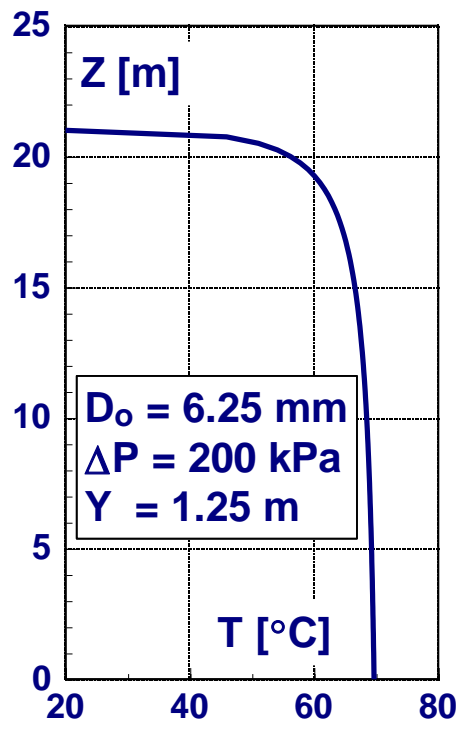

(b) Liquid film temperature

Figure 19: Thermal shielding performance for impinging spray curtain

\section{General conclusions}

Water spray curtain looks as good candidate to mitigate the consequence of major industrial hazards such as the release of heavy gaseous pollutant or the thermal radiation emitted by fire. The research programme carried out at the VKI in collaboration with the ICT, University Claude Bernard, CETHIL-INSA and EMA has led to the formation of a exhaustive data base, which has allowed the development and the validation of the engineering code CASIMIRE. This numerical tool can be used to design efficient water spray curtain to dilute gas cloud or to attenuate thermal radiative flux.

In the case of forced dilution of heavy gas cloud, the water curtain remains relevant for wind not exceeding $5 \mathrm{~m} / \mathrm{s}$.

In the case of thermal shielding, the impinging spray configuration afford much higher performance compare to the vertical spray arrangement, however the water consumption may double.

\section{References}

1. HALD, K. : Forced Dispersion of Heavy Gas Clouds by Water Curtains--Experimental and Numerical Approaches- PhD thesis, Université Jean Monnet de Saint-Etienne, France, July 2005.

2 ST-GEORGES M.: Etude Hydrodynamique des Pulvérisations Liquides pour Application aux Rideaux d'Eau. PhD thesis, Universitté Claude Bernard - Lyon 1, France, 1993. 
3 ST-GEORGES, M. and BUCHLIN, J-M.: " Heat transfer in liquid curtains mitigating pollutant releases". Loss Prevention and Safety Promotion in the Process Industries, Vol II, pp 495-506, Edited by Mewis, J.J.; Pasman, H.J. and De Rademaker, E.E. Elsevier Sciences 1995.

4 BUCHLIN J.-M. Mitigation of problem clouds. Journal of Loss Prevention in the Process Industries, (7):167-174, 1994.

5 BUCHLIN J.-M. \& ALESSANDRI E. Numerical simulation of the thermohydraulic behavior of liquid sprays. $13^{\text {th }}$ Annual Conference on Liquid Atomization and Spray Systems. Florence, Italy, July 1997.

6 ST GEORGES,M. and BUCHLIN, J-M.:" Detailed Single Spray Experimental Measurements and One-Dimensional Modeling”. Int. J. Multiphase Flow Vol. 20, No. 6, pp979-992, 1994.

7 ZIMMER, L, Étude numérique et expérimentale de la turbulence en écoulement gaz-gouttelettes. Applications aux rideaux d'eau en présence de vent latéral. $\mathrm{PhD}$ thesis l'Universitée Henri Poincaré, Nancy I, April 2001.

8 MALET, J, Pulvérisations de type jets-plats (Flat-fan Sprays), von Karman Institute, European Contract , Nov. 1999.

9 GRIOLET, F.; LIETO, J.; DEMBELE, S.; DELMAS, A.; RAYNAUD, M.; SACADURA, J-F.; PRÉTREL, H.; BUCHLIN, J-M.; RIETHMULLER, M.:" Mitigation of hazardous fire radiation by water spray curtain: A co-operative program to obtain engineering predictive model with laboratory and fields tests validation" $9^{\text {th }}$ Inter. Symp. on Loss Prevention, Safety Promotion in the Process Industries; Barcelona (Spain); 1998.

10 PRETREL $\mathrm{H}$. Étude du comportement thermo-hydraulique de pulvérisations liquides sous l'effet d'un rayonnement infrarouge. Application à la protection incendie par rideau d'eau. PhD thesis, von Karman Institute \& Institut des Sciences Appliquées, Université Claude Bernard de Lyon, 1997.

11 DEMBÉLÉ S. Modélisation et étude expérimentale des transferts de chaleur par rayonnement dans un rideau d'eau diphasique : application à la protection incendie d'installations industrielles à risques. PhD Thesis, Institut National des Sciences Appliquées de Lyon, France, 1998.

12 HALD, K. and BUCHLIN, J.-M.: Thermal Shielding by Water Spray Curtains. Eurotherm 73 on Computational Thermal Radiation in Participating Media, Mons, Belgium, 2003.

13 BUCHLIN J.-M. Thermal shielding by water spray curtains. Journal of Loss Prevention in the Process Industries, Volume 18, Issues 4-6, July-November 2005, Pages 423-432.

14 BUCHLIN, J.-M. (2001). Systèmes de Protection - Incendie par Rideau d'Eau et Film Liquides - ASTRE II ". VKI CR 2001-13.

15 CHANTRENNE, P. \& RAYNAUD, M. (1996). A new gauge for the measurement of radiative heat flux. 3rd Seminar European Research Industrial Fires, Roskilde, Denmark.. 